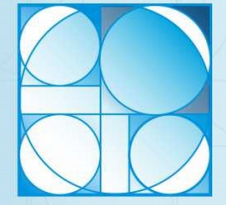

Editorial
Journal of Biochemistry Education

Revista de Ensino de Bioquímica

Revista de Enseñanza de Bioquímica

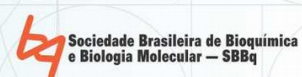

V. 16 N. E./ 2018

ISSN: 2318-8790

ISSN (until 2012): 1677-2318

\title{
Editorial 2018 - Especial
}

O número especial da REB é uma iniciativa da revista e da SBBq para valorizar e divulgar os trabalhos na área de ensino, apresentados nas reuniões anuais da Sociedade. Este número especial apresenta os sete resumos inscritos na área de Educação $(F)$, da $47^{a}$ Reunião da Anual da Sociedade Brasileira de Bioquímica e Biologia Molecular, realizada no Centro de Eventos de Joinville, SC, no período de 26 a 29 de junho de 2018.

As sessões de cartazes ocorreram nos dias 27 de maio (resumos $\mathrm{F}$ com números ímpares) e 28 de maio (resumos $\mathrm{F}$ com números pares). Nestas oportunidades, os autores e visitantes discutiram temas como:

F-01: Avaliações bioquímicas e fisiológicas em corredores de rua como estratégia educacional para minimizar a incidência de lesões e promover a saúde num nível inicial.

F-02: Jogo de tabuleiro como recurso educacional para a compreensão dos processos bioquímicos envolvidos na Síndrome Metabólica, Diabetes Mellitus, dislipidemia e obesidade.

F-03: Método colaborativo de ensino de Bioquímica, usando a literatura na forma de poesia, como ferramenta lúdica e eficiente de aprendizado.

F-04: Percepção de um grupo de alunos do ensino médio a respeito dos temas de Biologia Celular.

F-05: Auxílio de um monitor num programa de reforço extraclasse de bioquímica para alunos com dificuldade de aprendizado.

F-06: Contribuição do uso do PBD (Programa de dados sobre proteínas) para o ensino de doenças metabólicas num curso de nutrição.

F-07: Proposta de um método poligonal, no qual se representam grupamentos químicos com formas geométricas, para o ensino mais dinâmico do metabolismo.

Os trabalhos foram avaliados por um grupo sócios da SBBq que elegeram como melhor cartaz o F-3 - Biochemistry in poetry: A teaching experience using collaborative learning methodology to learning Biochemistry at the Medical School - Silvia Regina Tozato Prado, Pontifical Catholic University of Paraná, Medicine School (Paraná, Brasil).

No evento, também, ocorreu o simpósio "Bachelor of Biochemistry in Brazil" organizado por Bayardo Baptista Torres (IQ-USP), com os seguintes participantes:

- Valeria Monteze Guimaraes - Universidade Federal de Viçosa (MG, Brasil): Current panorama and challenges of the biochemical professional.

- Rafael Cesar Russo Chagas Universidade Federal de São João del-Rei (MG, Brasil): Current overview and challenges of the biochemistry course at UFSJ.

- Jurandir Fernando Comar - Departamento de Bioquímica, Universidade de Maringá (PR, Brasil): The bachelor degree in biochemistry at the university of maringá: challenges and prospects.

- John Donelson - Professor Emeritus of Biochemistry, University of lowa llowa City, lowa, USA) and Visiting Professor at, Universidade Federal do Rio Grande do Norte (Natal, RN, Brazil): 40 years of teaching biochemistry in the United States. 


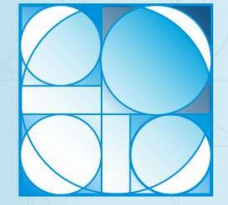

Editorial

\section{Journal of Biochemistry Education}

Revista de Ensino de Bioquímica

Revista de Enseñanza de Bioquímica

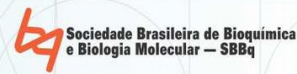

ISSN: 2318-8790

ISSN (until 2012): 1677-2318

Devido à gentil disponibilização de um espaço na área dos expositores, por parte da SBBq, a Revista de Ensino de Bioquímica realizou divulgações detalhadas dos seus diferentes modelos submissões, utilizando banners específicos.

Simultaneamente, foi aberto o Edital para o $2^{\circ}$ Prêmio Nacional de Ensino de Bioquímica e Biologia Molecular Bayardo Baptista Torres cujo objetivo é incentivar pesquisadores e professores a sistematizarem e compartilharem suas experiências envolvendo o ensinoaprendizagem do conteúdo abordado pelas áreas de Bioquímica e Biologia Molecular, seja no ensino básico ou superior.

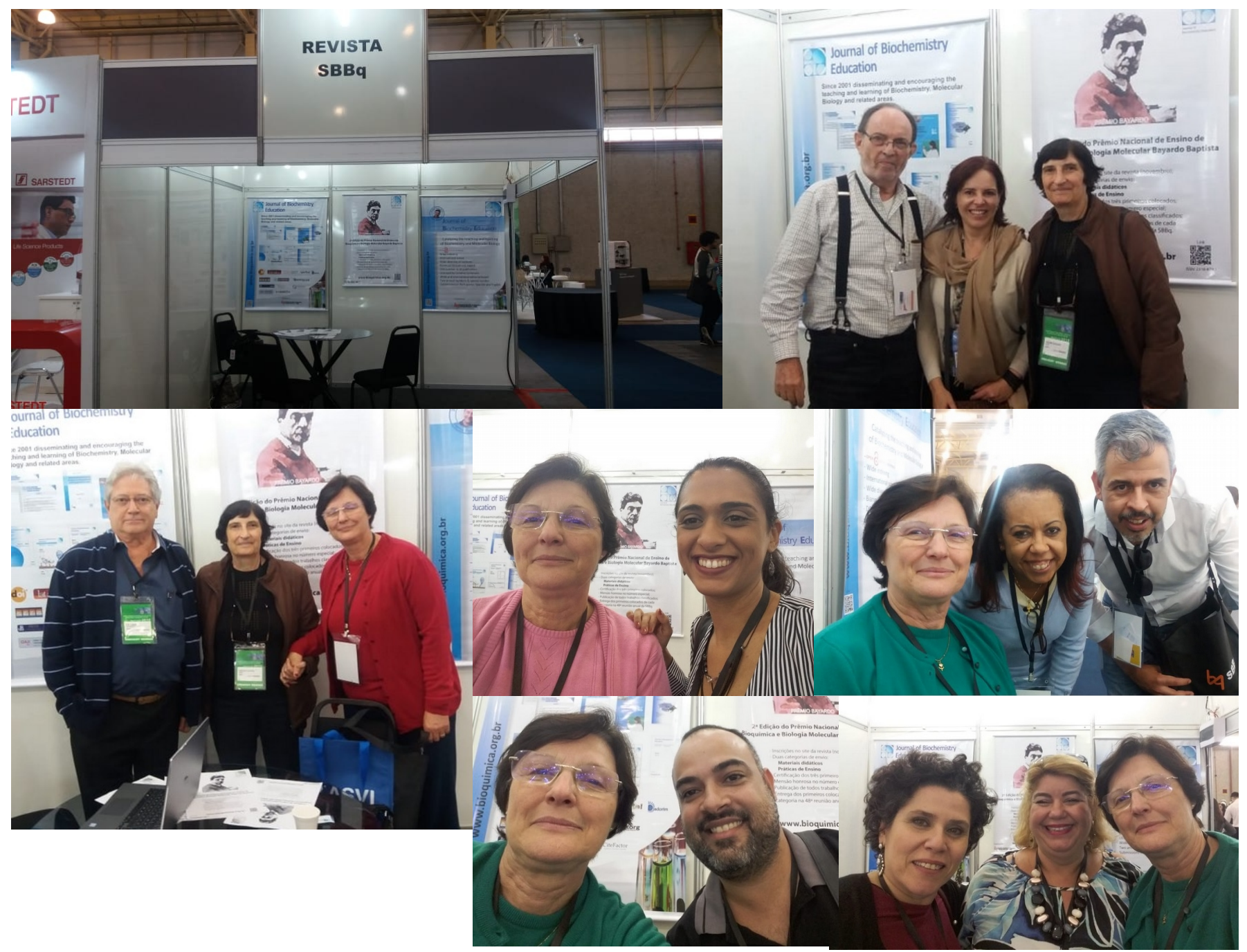

Como já está se tornando uma tradição, o estande serviu de ponto de encontro para troca de experiências de ensino-aprendizagem em Bioquímica e Biologia Molecular.

Atenciosamente

Gabriel G. Hornink

Unifal-MG

Editor-chefe

Vera Maria T. Trindade UFRGS

Co-editora

Bayardo B. Torres

USP

Editor-sênior

Eduardo Galembeck Unicamp

Co-editor
André Amaral Branco

Unifesp

Co-editor 